REVISTA CHILENA DE LITERATURA

Abril 2009, Número 74, 169 - 195

\title{
MIRAMONTES, ARMAS ANTÁRTICAS, FIRBAS
}

\author{
Gilberto Triviños y Edson Faúndez \\ Universidad de Concepción \\ gtrivino@udec.cl \\ efaundez@udec.cl
}

Lo que me importa es más bien la distribución de las fuerzas y los motivos en tal o cual obra, y reconocer lo que en ella es hegemónico o lo que se ve secundarizado, hasta negado.

Derrida

\section{RESUMEN / ABSTRACT}

La edición por primera vez completa de Armas antárticas de Juan de Miramontes y Zuázola (2006), que aquí provoca el diálogo productivo entre el poeta del siglo XVII, Paul Firbas, su editor del siglo XXI, y nosotros sus lectores, invita a pensar que no podemos aspirar al porvenir sin revisar críticamente las llamadas escrituras de la invención del Nuevo Mundo. La inscripción del relato de la "escena primordial" de Cajamarca (Canto I) en un contexto dialógico, cuya mayor consecuencia es revelar la imposibilidad del sueño colonial del "crimen perfecto" (mudez del vencido), da forma específica a dicho diálogo escrito entre la identificación y el distanciamiento de dos actos de escritura seductora: el poema de Miramontes y el estudio de Firbas.

Palabras clave: Armas antárticas, épica colonial, relato de Cajamarca, crimen (im)perfecto.

The first complete edition of Armas antárticas by Juan de Miramontes y Zuázola (2006), stimulates a productive dialogue between the $17^{\text {th }}$ century poet, Paul Firbas, its $21^{\text {st }}$ century editor and we, the readers, and invites us to think that we cannot aspire to the future without 
revising critically the written records of the invention of the New World. The inscription of the tale of the "primordial scene" of Cajamarca (Canto I) in a dialogic context, whose major consequence is to reveal the impossibility of the colonial dream of the "perfect crime" (the silence of the defeated), gives a specific form to said dialogue, written between the identifcation with and the distancing of these two acts of seductive writing: Miramontes 'poem and Firbas'study.

KEY WORDS: Armas antárticas, colonial epic, tale of Cajamarca, (Im)perfect crime.

La edición crítica de Armas antárticas ${ }^{1}$ constituye un acontecimiento de gran importancia para pensar nuestro "imprevisible por-venir" en la época de la imposibilidad de la irrupción del acontecimiento. El poema de Juan de Miramontes y el trabajo filológico de Paul Firbas testimonian que aún es posible la interrupción provocadora del continuum llamado huelga del acontecimien$t^{2}$. Obligan fundamentalmente a reflexionar sobre la herencia en "Nuestra América": ¿cuál es y dónde ésta?, ¿quiénes son sus legatarios?, ¿es posible transformarla? Derrida describe con precisión el doble imperativo puesto en juego por la edición completa, no fragmentaria, de uno de los poemas "más bellos" de la literatura colonial americana: "hay que saber y saber reafirmar lo que viene 'antes de nosotros', y que por tanto recibimos antes incluso de elegirlo, y comportarnos al respecto como sujetos libres (...) ¿Qué quiere decir reafirmar? No solo aceptar dicha herencia, sino reactivarla de otro modo y mantenerla con vida. No escogerla (porque lo que caracteriza la herencia es ante todo que no se la elige, es ella la que nos elige violentamente), sino escoger conservarla en vida" (Derrida y Roudinescu 12). El poema épico que ha ocupado un lugar marginal, prácticamente invisible, en el canon de la literatura latinoamericana, no está inmovilizado en un pasado sin ninguna

1 Juan de Miramontes Zuázola. Armas antárticas. Estudio, edición crítica y notas de Paul Firbas. Lima, Fondo Editorial de la Pontificia Universidad Católica del Perú, 2006

2 Jean Baudrillard escribe en La ilusión vital: "Podríamos hablar de una suerte de 'huelga de los acontecimientos', para utilizar la expresión de Macedonio Fernández. ¿Qué significa? Que el cometido de la historia ha acabado. Que el contenido del duelo ha comenzado. Que el sistema de información ha sustituido al de la historia y que está comenzando a producir acontecimientos de la misma forma que el Capital ha comenzado a producir Trabajo. Al igual que el trabajo, bajo estas circunstancias, ya no tiene significado por sí mismo, el acontecimiento producido por la información ya no tiene ningún significado histórico por sí mismo" (44-45). 
relación con el presente y el futuro. Es, por el contrario, un "texto fundacional" que hoy, por, a través y con Firbas, nos exhorta a reapropiarnos de él a la vez que a reinterpretarlo de tal modo que tenga lugar un cambio en nuestros modos de re-pensar el legado colonial. Aquí, en esta doble relación con la herencia, reside el experimento, en el sentido de Deleuze, de este artículo: conectar la escritura de Miramontes con la de Firbas y con la nuestra para que algo, que no es de uno ni de otro sino de todos, se produzca: un saber acaso terrible sobre el poder de la letra en la construcción de las alteridades en Armas antárticas, pero de intensa contemporaneidad en esta "era del exterminio del Otro (...), equivalente a una purificación étnica que no solo afectara a unas poblaciones concretas, sino que se encarnizara con todas las formas de alteridad" (Baudrillard, El crimen perfecto 149). No, pues, el puro comentario ("ique aburrimiento!") de la edición crítica de un texto complementada por un extenso aparato de notas. Tampoco el catálogo detallado de los méritos del estudio preliminar ya imprescindible sobre el género épico en relación con la imaginación del imperio y la colonia hacia finales del siglo XVI. Se trata de una operación mucho más sencilla y más compleja a la vez: aceptar la doble invitación de Firbas: "Dejo ahora al lector con las octavas de Armas antárticas, abiertas a la lectura poética y el diálogo crítico" (115). Placer del texto y diálogo crítico: ¿boda contra natura entre ética y estética? ¿Posibilidad de conciliar el goce de la belleza de una obra de arte con el rechazo de la negación radical del otro que la funda? Dos figuras son en todo caso relevantes en este aspecto: seducción y diálogo. Conocemos, por la primera, el poema completo, gozamos sin pudor su belleza, nos exponemos a las trampas de su seducción, pero también intentamos la reversión de los signos que lo constituyen. Reafirmación y reelaboración de la herencia. Renunciamos, por la segunda, a hablar sobre el poema de Miramontes y sobre el estudio de Firbas, asignándonos una autoridad filológica y superioridad crítica que no tenemos. Preferimos hallar, encontrar, robar a uno y otro en vez de glosar, juzgar, resolver. Eso que los autores de Diálogos llaman poner en movimiento un bloque que ya no es de nadie, sino que está entre todos, como un barquito que unos niños sueltan y pierden, y que otros roban (Deleuze y Parnet 14). El barquito de la reelaboración de la memoria colonial, en este caso, que permite (re)descubrir en Armas antárticas que "los rastros del futuro están en el pasado" (Piglia 99), que "las fuerzas apagadas son el mejor combustible para los nuevos fuegos.// La llama solo se enciende con su pasado" (Juarroz 16). 
Debemos a Franklin Pease García-Irigoyen (1939-1999), director del Fondo Editorial de la Pontificia Universidad Católica del Perú y ferviente estudioso de las fuentes coloniales, la sugerencia de publicar Armas antárticas $^{3}$ en la valiosa Colección Clásicos Peruanos por él fundada. El trabajo de Paul Firbas, intelectual peruano radicado en Estados Unidos, continúa y concluye en este aspecto la ardua tarea filológica de Jacinto Jijón y Caamaño (1921), José Toribio Medina (1924) y Rodrigo Miró (1978). Los responsables del mencionado Fondo Editorial celebran así la publicación de un "texto fundacional" para el Perú: "La presente edición crítica (...) no solo es la primera publicada en el Perú, sino también la primera en ofrecer un texto rigurosamente establecido, complementado por un extenso aparato de notas filológicas y de comentario que facilitan su lectura y establecen las complejas conexiones con las culturas europeas y americanas" (Miramontes, Contratapa). La primera edición también, podría decirse, que testimonia en acto el prodigio recordado por Bajtin: "no existe nada muerto de una manera absoluta: cada sentido tendrá su fiesta de resurrección. Problema del gran tiempo" (Estética de la creación verbal 393).

El valioso estudio inaugural de esta edición crítica sitúa el poema de Miramontes precisamente en el "gran tiempo" de la épica culta renacentista (Orlando Furioso), los modelos de la epopeya histórica (La Araucana, Os Lusíadas) y la tradición épica latina (Eneida, Farsalia). Su autor establece el carácter singular de la épica colonial, destacando sobre todo los problemas éticos inmanentes a la cristalización del discurso heroico en el Nuevo Mundo. ¿Son estas problemáticas solo signos distintivos del discurso épico de los siglos XVI y XVII o pruebas irrefutables del fracaso de todo intento discursivo occidental de conciliar la naturaleza del gran arte con la índole inhumana del colonialismo? No es el momento de detallar aquí las posiciones y lecturas generadas por esta interrogante. Las conclusiones de Firbas sobre el proyecto poético de construir Armas antárticas como lugar de la memoria con la elevación y la perennidad de un monumento son en todo caso profundamente sugestivas: el canto de "los hechos de los famosos capitanes españoles que se hallaron en la conquista del Perú” está logrado en el poema de Miramontes. No así, en cambio, el canto del mundo antártico:

3 La edición crítica de Armas antárticas, en primera instancia, corresponde a la monografía "reelaborada" -y por lo tanto "un nuevo texto- con la que Paul Firbas obtiene al grado académico de Doctor (2001, Universidad de Princeton). 
(el) mundo de los españoles antárticos es un espacio en crisis. Miramontes encuentra las armas abandonadas en América, los mares invadidos de piratas, el espacio americano inacabado y abierto en sus dos 'puertas' -Panamá y Magallanes-a las invasiones inglesas. El poema se enuncia desde ese lugar poroso y heterogéneo, y las octavas quieren darle el orden, cerrazón y coherencia que no posee. En última instancia, el texto busca cerrar los vacíos y consolidar el imperio desde la colonia, pero no lo logra completamente -acaso sí en la región andina-, en parte porque no consigue la distancia y plenitud de un monumento. A diferencia de la fundación inicial del Perú de los conquistadores, plenamente acabada en la imaginación del texto, la fundación del mundo antártico quedará truncada. El amplio mapa que el poema dibuja no consigue incorporar las tierras incógnitas: el espacio antártico mantiene sus fisuras, atravesado por los nuevos imperios de finales del siglo XVI (Firbas 82).

Escritura plena de la fundación poética de la conquista del Perú, pero escritura trunca de la fundación poética de la defensa del mundo antártico. Aquí reside, sin duda, el punctum más provocador de las ideas de Firbas. Nosotros, ladrones de pensamientos, pero no de almas, las robamos sin pudor. Nos apropiamos de ellas precisamente ahí donde el editor consuma el gesto simbólico de abrir el texto a la lectura poética y al diálogo crítico. Nuestro homenaje a la finura del estudio de Firbas no puede ser otro que robarle su presa (justo ideas y no ideas justas) y aumentarla para ser robados a la vez: "Bodas, pero no parejas ni conjugalidad. Tener un saco en el que meto todo lo que encuentro, pero a condición de que también me metan a mí en un saco" (Deleuze y Parnet 13). El barquito otra vez: Miramontes $y$ Firbas $y$ nosotros. Cada uno lleva su botín, sin dejar por ello de juntarse para pensar entre todos lo que parece constituir el secreto deseo de la poesía épica colonial de los siglos XVI y XVII: consumar el crimen perfecto. La mudez sin cese de los vencidos. Eso que el cronista del "exterminio del Otro" en nuestra época, llama estasis definitiva y metástasis del Mismo: "Se acabó el otro... Se acabó el enemigo...Se acabó el predador...Se acabó la negatividad... Se acabó la alteridad... Se acabó la seducción... El crimen perfecto" (Baudrillard, El crimen perfecto 150$)$. 
Tres son las figuras más inquietantes de la alteridad inasimilable en el espacio heroico fabulado en Armas antárticas": los ingleses "luteranos", los negros cimarrones y los indios magallánicos. Los "indios peruanos", en cambio, no ocupan ya el epicentro épico de Armas antárticas. Ni perturban ni asombran la escritura de Miramontes. Nada evoca en ellos los atributos de sus dobles sublimes en los relatos del mundo andino del Inca Garcilaso o de Cieza de León. Su metamorfosis en obedientes "ovejas de Cristo" los integra en el espacio de la "evangélica semilla" sembrada por "la mano del católico reino de Castilla", pero clausura su presencia "feroz y con soberbio aspeto" en la narración de las victorias "más grandes y singulares" de los españoles en el Nuevo Mundo.

El relato de la época de la conquista que Firbas llama período de "la primera fundación mítica del Perú" ocupa solo los dos primeros cantos de Armas antárticas. Su cierre, coincidente con la evocación del "torpe, inútil ocio y pereza" de los conquistadores del mundo andino, señala simultáneamente el lugar exacto de la desaparición de los "indios peruanos" en el "segundo ciclo (épico) y también la segunda fundación” de Perú: "los pobladores indígenas de los Andes desaparecen sin dejar ninguna zona de probable encuentro con el mundo español. La única forma de acceder a ellos es a través de la narración oral del general Pedro de Arana. En el momento que dejan de ser los enemigos pierden su lugar en los versos heroicos" (102). Ahí, en el espacio del mito, no ya de la historia, Miramontes construye, según Firbas, una imagen ideal de los "bárbaros valientes" que busca, de alguna manera, hacer perdurable en el poema, acaso para compensar imaginariamente su ausencia, la memoria del rostro indio derrotado y martirizado del Canto I de Armas antárticas.

La ficcionalización de los indios peruanos en Armas antárticas testimonia ejemplarmente la tentación propia del pensamiento occidental: la transfiguración del otro en prójimo. Tentación difícil de evitar, porque la alteridad radical constituye siempre una provocación destinada a la reducción y al olvido en el análisis, la memoria y la historia (Baudrillard y Guillaume 1213). La pulsión etnófaga que consume y consuma la escritura de Miramontes es ostentosa en la programación misma del poema: las "voces insolentes" del

4 Las citas de Armas antárticas corresponden a la mencionada edición crítica de Paul Firbas. 
indio están "agora mudas". Las "proezas militares" de los conquistadores, materia por excelencia del canto épico en el Nuevo Mundo, han puesto ya el Verbo eterno en los altares de los oráculos gentílicos. Arauco (está) domado, proclama Pedro de Oña en las postrimerías del siglo XVI. El "indio pirüano" también, replica felizmente Miramontes en los inicios del siglo XVII. El espejismo colonial que rige la escritura de uno y otro poema épico es el mismo: el mito de la obediencia sin residuos de las "remotas gentes" indianas, la ilusión de la feliz metamorfosis de los airados "pechos idólatras" en mansas "ovejas de Cristo". La ficción de la estabilidad colonial adquiere en este caso la forma de una sobrecodificación social y religiosa que convierte al indio dom(in)ado en una diferencia regulada ${ }^{5}$. Es la reducción del otro, precisamente, que Carlomagno, en La chanson de Roland, intenta inútilmente producir en su enfrentamiento con Baligán: "Recibe tú la ley que Dios nos reveló, / la fe del cristianismo, y al punto te amaré" (228). Imagen seductora que hace pensar a Pedro Henríquez Ureña que los colonizadores "acabaron por sentir que trataban con hombres iguales a ellos mismos" (41).

La lectura de Firbas privilegia el episodio de la prisión y condena a la hoguera del lengua Felipe como clave mayor para determinar la visión crítica de Miramontes en el relato de la conquista del Perú (Cantos I y II). $\mathrm{Su}$ idea más sugestiva en este aspecto es que el lascasismo de Felipe es el artificio poético y político mediante el cual el representante letrado de la elite emergente intenta deslegitimar el poder de los primeros conquistadores y sus descendientes directos. La función de Felipe en dicho artificio es siempre la misma: traducir, ser lengua de Atahualpa y Valverde, de Dios y de Bartolomé de las Casas:

5 Existe en todo otro, según Baudrillard y Guillaume, "el prójimo -ése que no es yo, ése que es diferente de mí, pero al que, sin embargo, puedo comprender, ver y asimilar- y también una alteridad radical, inasimilable, incomprensible e incluso impensable" (12). Aquí reside tal vez uno de los mayores espejismos del poema de Miramontes: la ilusión colonial de la reducción para siempre de la "alteridad radical" de los indios peruanos. Estas "mansas ovejas" son ya figuras del prójimo que debe ser aceptado y respetado en sus diferencias. No así los luteranos, cimarrones y bárbaros magallánicos, quienes representan no la reducción del otro a prójimo, sino la inasimilable alteridad radical. Sobre ellos el poema descarga su violencia verbal. mostrando sin velos que la alteridad irreductible a las formas de un intercambio regulado es siempre el epicentro de un terror. El terror que ella produce y el terror que sobre ella se despliega. 
Parece claro que el artificio de Miramontes consiste en convertir a Felipe en una voz que surge desde el mismo campo de batalla para criticar, desde allí, los excesos -también fundacionales- de la conquista. A través de este personaje, Miramontes interviene en el debate sobre la legitimidad de la conquista desde la perspectiva de un nuevo sector de la elite colonial, situado críticamente respecto de los viejos conquistadores y encomenderos. Como un oráculo, Felipe se anticipa a la muerte de Pizarro y comunica la justicia divina. Armas antárticas asume la muerte del Inca como una escena revestida de pecado e ilegitimidad. Finalmente, el mismo cuerpo de Felipe, quemado en el castigo, expresa el final de los incas. El mundo andino queda hecho cenizas: y como el ave Fénix, va a renacer en el mito (Firbas 104-105).

Esta lectura es, sin duda, persuasiva. Nada impide afirmar, por ejemplo, que Armas antárticas es una bella expresión literaria y política de los empeños de la nueva aristocracia letrada del virreinato del Perú para construir su propio "discurso simbólico" en la época de las disputas territoriales de las potencias europeas por la posesión de América. Es posible, no obstante, profundizar aún más en el estudio del episodio del "indio infame". Se trata, en cualquier caso, de no olvidar que el episodio de la condena y muerte del traidor es solo uno entre muchos episodios constitutivos de la "escena primordial" de la conquista del Perú: la catástrofe de Cajamarca. La cuestión importante es por ello conectar dichos momentos entre sí para ampliar más el espectro de los sentidos del texto, sobre todo aquéllos que el lector-escritor Miramontes intenta inútilmente silenciar para exaltar épicamente a la nueva elite colonial necesitada de legitimación simbólica. Aquí, en esta conexión, se juega el interés de nuestra participación en el barquito de nuestra herencia colonial: robamos pensamientos, nos apropiamos de ellos, pero solo para reelaborarlos de otro modo: Deleuze y la conjunción $Y$. Pero también Derrida y la herencia.

Hay un "grado cero" del encuentro de la oralidad y la escritura en la historia del Nuevo Mundo. Un momento en el cual la una y la otra no solo marcan sus diferencias extremas sino su recíproca y agresiva repulsión. Tal punto de fricción total, dice Antonio Cornejo Polar, tiene una fecha, unas circunstancias y unos personajes muy concretos. Es el diálogo en Cajamarca entre Pizarro y Atahualpa, mediado por el sacerdote Valverde y traducido por el indio Felipe, la tarde del sábado 16 de noviembre de 1532. El autor de Escribir en el aire describe así el núcleo persistente de las múltiples versiones cronísticas del "encuentro" inaugural de la voz y la letra en el mundo andino: 
(A) través de un intérprete, Valverde requiere la sujeción del Inca a las creencias cristianas y al orden de la España imperial, le entrega un libro sagrado (presumiblemente la Biblia o un breviario) que Atahuallpa termina por lanzar al suelo. Con matices de más o menos, ese acto es suficiente para que se desencadene la violencia del aparato militar de los conquistadores... (El) libro no dice nada a quien sintetiza en ese momento la experiencia cultural nativa, con lo que él y su pueblo quedan sujetos a un nuevo poder, que se plasma en la letra, y marginados de una historia que también se construye con los atributos de la lengua escrita. De una u otra manera, los cronistas hispanos consideran que el Inca 'fracasó' ante el alfabeto y es obvio que su 'ignorancia'-de ese código específico-situaba a él y los suyos en el mundo de la barbarie: en otras palabras, como objetos pasibles de legítima conquista. Por supuesto, el poder de la letra y el derecho de conquista tienen un contenido político pero también un sentido religioso. En efecto, si como señala Mac Cormack, para Atahualpa 'el libro tuvo que ser un objeto, no un texto', no hay duda de que ese objeto era sagrado, puesto que de dioses se le estaba hablando; por consiguiente, su 'fracaso' tuvo una dimensión sagrada, religiosa o divina definida por su incapacidad de 'entender' la palabra de Dios que generosamente se le estaba ofreciendo. Al ignorar la letra, Atahuallpa está ignorando a la vez al rey y a Dios: doble ignorancia que, en la época, se confunde en un solo pecado imperdonable (Cornejo Polar 32-38).

El poema de Miramontes parece reproducir sin transformaciones significativas el elemento invariante de las crónicas hispánicas del "diálogo" de Cajamarca, con la excepción de la Crónica del Perú del Inca Garcilaso. $\mathrm{Su}$ especificidad más evidente reside, con todo, en la forma explícita de la relación inequívocamente directa entre la afrenta incaica y el castigo español del 16 de noviembre de 1532: "Pidió el Rey y tomole el breviario, /abriole prasumiendo que hable, / que verbalmente el bárbaro entendía / como oráculo hablaba y respondía // Echole en tierra. 'Ni habla ni responde, / dijo, (...) Indignose de aquesto el religioso, / y a un tiempo manos y ojos levantando/ al todo en tierra y cielo poderoso, / humilde estas palabras dijo, orando: (...) / Tú, Dios de los ejércitos, que diste / victoria a Jedeón contra millares; / (...) / te suplico esta ofensa satisfagas, / ésta entre tantas maravillas, hagas" (octavas 25 - 30). Los episodios del rechazo inca del Libro ("Echóle en tierra"), la cólera de Valverde ("Indignose de esto el religioso"), su imploración al "Dios de los ejércitos", la represalia española (mortandad y 
prisión del Inca) y la prisión y muerte de Atahualpa son también claves para el estudio del relato de la conquista de Perú en Armas antárticas. La fuerza seductora del poema se manifiesta en toda su plenitud cuando dicho análisis privilegia solo el episodio de la condena, profecía y muerte de Felipe, sin advertir que dicha preeminencia muestra que se ha entrado peligrosamente en el espacio de una trampa meticulosamente preparada por Miramontes en el relato de la tragedia de Cajamarca. Las palabras ofensa (india) y castigo (español) de la octava 37 testimonian nítidamente que las emanaciones del perfume de la pantera (Baudrillard, De la seducción 1998) ${ }^{6}$ existen ya en los momentos iniciales del relato de la "escena primordial" de la conquista del Perú, mucho más acá y más allá del episodio del "indio infame". Armas antárticas legitima, en efecto, la hecatombe narrada con solo el empleo de las dos palabras cruciales. El origen de la violencia en Cajamarca, dice el narrador, es la ofensa inca del Libro y su castigo. Ofensa, esto es, injuria "contra razón y justicia" y castigo, esto es, "pena que se impone al que ha cometido un delito o falta" (Diccionario de Autoridades). El Gran Intérprete, el Gran Traductor del Canto I del poema de Miramontes no es realmente "Filipe el indio infame, cristiano ya". Es Valverde, el sacerdote iluminado que suplica a Dios castigar la ofensa del "(rey) bárbaro". Aquí reside, por lo demás, la paradoja trágica de la escena primordial peruana. La divinidad que escucha la súplica de su airado intérprete no está llena de la mansedumbre que le atribuye el requerimiento de obediencia a Atahualpa. Es el "Dios de los ejércitos" que hace tronar vientos y nubes, temblar el suelo y hundirse el turquesado mar cuando "en los cristianos pechos ira infunde, / por do un valiente esfuerzo, ardiente celo / de hacer cruda venganza en todos cunde, / y acércanse al combate frente a frente / de aquel grueso escuadrón de inmensa

6 La leyenda de la pantera perfumada permite a Baudrillard descubrir la naturaleza reversible de la "fuerza de atracción y de distracción, fuerza de absorción y de fascinación, fuerza de derrumbamiento (...) de todo lo real" (De la seducción 79) que llamamos seducción: "La atracción inmediata del canto, de la voz, del perfume. La de la pantera perfumada (...) Según los antiguos, la pantera es el único animal que emana un olor perfumado. Utiliza ese perfume para capturar a sus víctimas. Le basta esconderse (pues su visión les aterroriza), y su perfume les embruja - trampa invisible en la que caen. Pero este poder de seducción puede volverse contra ella: se la caza atrayéndola con perfumes y aromas" (De la seducción 74). Nuestra lectura de Armas antárticas como pantera poseedora de una fuerza de atracción y de distracción (el "embrujo de la belleza" de su lenguaje poético), que puede tornarse contra ella por el llamado ciclo de la reversión de los signos, se funda en dicha historia de "los antiguos". 
gente" (octava 31). Negocio divino: término de la Tiranía de Satanás, inicio del Gobierno de Cristo: mundo nuevo que Dios dona a los españoles para premiar su virtud en la guerra santa contra los musulmanes en España. El mito de la nación elegida, sin el cual es impensable el espejismo épico español en el relato de la Conquista, predomina de tal modo en Armas antárticas que llega a constituir el principio unificador de las "cuatro zonas narrativas del poema vinculadas con las posibles etapas de su redacción” (Firbas 29-30): el cuento que profetiza en el pasado prehispánico el dominio de los "memorables españoles (...) inspirados de un Dios omnipotente" (Cantos XIII-XVII), la epopeya trágica de la conquista del Perú (Cantos I-II), la epopeya de su defensa y la tragedia de sus fundaciones en su extremo austral (Cantos III-X, XVIII-XX). No hay en este aspecto dispersión ni desorden entre las zonas narrativas así integradas. La maestría de Miramontes en este aspecto parece residir fundamentalmente en la creación de un nexo profundo entre las historias por él contadas, en el trazado de una unidad secreta de la diversidad de espacios y tiempos de los bloques narrativos de su poema. Tal principio estructurante es precisamente el mencionado mito de la nación de España elegida por Dios para realizar su divino negocio en el mundo: relato legitimante del dominio español del Nuevo Mundo a la vez que del canto épico de su conquista, aquietamiento y defensa. Mito que, como en La Araucana, Arauco domado, Espejo de paciencia o Bernardo del Carpio nada interroga, nada subvierte, ni siquiera la profecía del "indio infame" que deja a Pizarro "triste (...) en su pecho compungido" (octava 62).

El discurso de Felipe parece ser el único elemento discordante en la glorificación del orden colonial español inaugurado por la catástrofe de 1532 en Cajamarca (Canto I) y simbolizado por la "mansa paz" y esplendor de Lima, nueva Atenas (Canto XIII). Un lugar del ya señalado poder seductor del texto para atraer hacia la verdad ${ }^{7}$ del escritor, que es la verdad de la elite colonial por él artísticamente elaborada, es en este aspecto particularmente polémico. Es la octava 61. El condenado a morir "en fuego" revela en ella la analogía,

7 "La seducción, al no detenerse nunca en la verdad de los signos, sino en el engaño y el secreto, inaugura un modo de circulación secreto y ritual, una especie de iniciación inmediata que solo obedece a sus propias reglas de juego. Ser seducido es ser desviado de su verdad. Seducir es apartar al otro de su verdad (...) La seducción es inmediatamente reversible, su reversibilidad proviene del desafío que implica y del secreto en el que se sume" (Baudrillard 1998: 79). 
la semejanza que consuma de modo definitivo la destrucción del aura épica de Francisco Pizarro: "pequé y en mí ejecutas tu sentencia, / pecaste y llegará la de tu muerte". El héroe de Cajamarca deviene así el doble monstruoso del traidor de Cajamarca. El narrador del Canto I no niega la verdad de esta escandalosa revelación. Le otorga, por el contrario, el prestigio de traducir la palabra divina: "Oh, Filipe!, propheta fuiste, y ello / verse ha en lo que adelante ha sucedido, / pues Marqués y Virrey, el pecho abierto, / a hierro fue Pizarro también muerto" (octava 62). Esta es la trampa seductora del poema leído como dispositivo retórico cuyo fin estético-político es atraer hacia la verdad de la elite que en él busca su legitimación simbólica. Su importancia no es accesoria ni solo válida para la comprensión del Canto I. El proyecto épico que genera la escritura del poema depende, por el contrario, de la duración sin fisuras del embrujo que paraliza la lectura crítica del episodio protagonizado por Felipe. El rechazo de la atracción inmediata del "canto, la voz, el perfume" de la pantera llamada Armas antártica, que aquí intentamos, suspende el embrujo de su belleza seductora, pero no se sitúa fuera de la lógica misma del ritual de juego y desafío que llamamos seducción. Ocurre, por el contrario, dentro de un proceso circular y reversible cuya ley es un intercambio ritual ininterrumpido, un envite donde la suerte del que seduce y la del que es seducido nunca está echada (Baudrillard, De la seducción 28). La fuerza de atracción y derrumbamiento de la pantera puede, pues, volverse contra ella. Puede cazarse atrayéndola con aromas y perfumes. Lo que interesa, en todo caso, es que, sin arrogarnos el poder verbal de emanar perfumes embrujadores, la suspensión de los efectos del engaño lascasista abre un vértigo de interrogantes sin fin a la verdad que funda a la vez el contracanto (armas andinas) y el canto (armas antárticas) del poema. Todas ellas, no obstante su diversidad, envían a lo mismo: lo borrado, lo tachado en el artificio descrito por Firbas. ¿Por qué Miramontes convierte en traductor de los designios de Dios a un personaje estigmatizado una y otra vez por las cronistas de los siglos XVI y XVII? ¿Por qué la imaginación analogizante del autor de Armas Antárticas no descubre que la cruel muerte de Atahualpa en Cajamarca (Canto I) es el espejo en el que debe leerse la cruel muerte de Túpac Amaru en Vilcabamba (Canto XIII)? ¿Por qué ninguna figura profética del relato de la defensa del Perú, no ya de su conquista, profetiza el fin también "desastrado" del virrey que desprecia las súplicas de no ejecutar al último Inca? ¿Por qué el canto de las figuras paradigmáticas de las "armas antárticas" olvida la función protagónica de Óñez de Loyola y de Sarmiento de Gamboa en la "hazaña" de la derrota, prisión y muerte de Túpac Amaru? 
¿El "Dios de los ejércitos" castiga los excesos de los conquistadores de Perú mientras permanece mudo con los excesos de sus defensores? ¿Es pecado la muerte de la piedad con los "pobres indios" en Cajamarca, pero no con los de Vilcabamba?

Acaso hay un hilo de Ariadna para guiarnos en el laberinto de los sentidos de Armas antárticas liberados por la suspensión inmediata del embrujo que podríamos denominar efecto de sublimación, propio de las escrituras fundacionales de todos los Estados nuevos y antiguos: "Todos los Estados-nación, nacen y se fundan en la violencia (...) Tienen su origen, aun antes de las formas modernas de lo que se llama, en sentido estricto, colonialismo, en una agresión de tipo colonial. Esta violencia fundadora no es solo olvidada. La fundación se hace para ocultarla; tiende por esencia a organizar la amnesia, a veces bajo la celebración y la sublimación de los grandes acontecimientos" (Derrida, El siglo y el perdón 36). Ese hilo no es otro que la inscripción del poema, específicamente el relato de la "escena primordial" de la conquista del Perú, en el "contexto dialógico" de la época de su escritura. Advertiremos entonces la doble fractura del proyecto sublimizador de Miramontes. La imposibilidad de cerrar las fisuras del mundo antártico (Firbas), pero también la de cerrar las fisuras del mundo andino.

La incomunicación con la cual se inicia la historia del "diálogo" tan duradero y traumático que llega hasta hoy (Cornejo Polar 36) es perceptible con nitidez estremecedora en el poema que comienza significativamente con el relato del triunfo de la letra herida por la voz sacrílega del Inca: "Las armas y proezas militares / de españoles cathólicos valientes / que por ignotos y soberbios mares / fueron a dominar remotas gentes, / poniendo al Verbo eterno en los altares / que otro tiempo, con voces insolentes, / de oráculos gentílicos espanto / eran del indio (agora mudas), canto" (octava 1). Agora mudas. Poder de la letra: derecho de conquista: silenciamiento de las voces insolentes. Los "indios peruanos" hablan, no obstante, en el poema, pero solo en el mito anterior a la historia. Hablan asimismo en el tiempo de la violencia fundadora del Perú colonial. Se trata, no obstante, del artificio mediante el cual, en la lectura de Firbas, el autor de Armas antárticas interviene en el debate sobre la legitimidad de la conquista desde la perspectiva de un nuevo grupo de la elite colonial. Felipe, en este caso, es solo la máscara de las Casas. Es posible, empero, leer en la palabra india así silenciada, expulsada al tiempo del mito o ideológicamente manipulada, otra significación que la de permitir a Miramontes criticar (solo) los excesos de los primeros conquistadores. Esa otra cosa no es más que la voz andina. No 
ya la traducción de la verdad del poseedor de la letra sino la expresión de la verdad de los vencidos que se desliza subrepticiamente entre los intersticios del relato sublimador de la violencia colonial. Producir el encuentro polémico del poema de Miramontes con las crónicas españolas, indias y mestizas de su época tiene en este aspecto gran interés. El flujo de las "voces insolentes", que el relato de las empresas memorables de los defensores del Perú intenta silenciar, se hace entonces audible. Ostentosamente audible ahí mismo donde se proclama su mudez.

Dos ejemplos, entre otros muchos, testimonian los efectos perturbadores de dicho encuentro en el continuum monólogico de Armas antárticas:

1. Atahuallpa habla por primera y última vez en el momento del sacrilegio de la escritura de Dios, no como Felipe, que habla en el de su ejecución. La descripción de su sueño con un Dios horrible e iracundo, "que temor (le) dio el velle, ólle pena" (octava 28), es radicalmente opuesta a los atributos de la divinidad del mito imperial glorificada por Valverde. ¿Crítica de los excesos de los conquistadores o de la norma de la conquista? ¿Felipe, entonces, no es la única palabra india disolvente del Canto I? La confrontación de las últimas palabras del Inca de Armas antárticas con las también últimas del Inca de Crónica del Perú, Tercera Parte, de Pedro de Cieza de León produce, con todo, el estallido del mayor espejismo de la elite colonial celebrada en Armas antárticas:: "(Atabalipa) yva diziendo por el camino estas palabras formales: 'Por qué me matan a mí?, ¿a mí por qué me matan? ¿Qué he hecho yo, mis hijos, mis mujeres?' y otras palabras destas (...) Luego lo ahogaron, e por cumplir la (sentencia) le quemaron con unas pajas algunos de los cavellos, que fue otro desatino; dizen algunos de los yndios que Atavalipa dixo antes que le matasen que le aguardasen en Quito, que allá le bolverían a ver hecho culebra. Dichos de ellos deven de ser" (Cieza de León 170). El distanciamiento del cronista que narra los inquietantes "dichos (que) de ellos deven de ser" no oculta el principio constitutivo de las relaciones entre oralidad y escritura fundadas por su trágico "encuentro" en Cajamarca. Revela, sin velos, la fricción, el abismo que las escinde. Una dice que el Inca ha muerto sin más; la otra, que ha muerto, pero renacerá.

Las significaciones de la inscripción de Armas antárticas dentro del contexto dialógico de su época son múltiples. Una de ellas es, con todo, la que más perturba el mecanismo cosificador propio del monologismo del 
poema ${ }^{8}$. Es precisamente la revelación de lo negado en el canto de "los hechos de muchos valientes españoles": la mudez del otro es un espejismo, el crimen de su desaparición es siempre imperfecto. Las voces de los vencidos, representadas por Atahualpa y Felipe más allá de los designios explícitos de Miramontes, persisten indestructibles en el mito, la historia y la literatura. Un pensador de nuestra época emplea dos nombres para designar esta "fatalidad indestructible de la Alteridad" en el mundo colonial: Gran Juego, Regla del Mundo: "De una parte, el Otro siempre está muerto; de la otra, es indestructible" (Baudrillard, La transparencia del mal 156). "Indestructibilidad". Poder de la idea, poder de los hechos, dice Baudrillard. Nosotros agregamos poder de la literatura, bellamente testimoniado por las figuras de Atahualpa y Felipe en Armas antárticas y mucho antes por Lautaro en La Araucana de Ercilla: "muertos podremos ser, mas no vencidos, / ni los ánimos libres oprimidos" (1962, Canto XXVI: 359).

2. La confrontación de Armas antárticas y Primer nueva corónica y buen gobierno, que sus autores terminan de escribir entre la primera y segunda década del siglo XVII, ilumina de modo igualmente ejemplar las estrategias de la voz para sobrevivir la opresión de la letra en el Nuevo Mundo. El abismo que escinde las relatos de Miramontes y Guaman Poma de Ayala en el denso y tenso tapiz de discursos orales y escritos, españoles y criollos, indios y mestizos del mundo andino adopta también en este caso la figura de dos interpretaciones simétricamente inversas de la tragedia de Cajamarca. Armas antárticas proclama en 1609 la mudez de las insolentes voces de los indios peruanos. Primer nueva corónica y buen gobierno deshace en 1615 el espejismo. Las voces de los sobrevivientes del mundo andino persisten desorientadas, clandestinas, reprimidas, extirpadas, pero ni calladas ni silenciosas, como hoy lo evidencian, entre otros muchos, los testimonios

8 "En el límite, el monologismo rechaza la existencia al exterior de sí mismo de otra conciencia con iguales derechos a responder, de otro yo con plenos derechos (un tú). En una aproximación (limítrofe o depurada), el otro permanece plenamente tan solo como objeto de la conciencia, pero no como otra conciencia. El monólogo es concluso y sordo hacia la respuesta ajena, no la espera y no reconoce su fuerza decisiva. El monólogo se las arregla sin el otro y por lo mismo en cierta medida a toda realidad. El monólogo pretende ser la última palabra. Clausura el mundo representado y a las personas representadas" (Bajtin, Yo también soy (Fragmentos sobre el otro) 164). 
recogidos por Ortiz Rescaniere (1973), Watchel (1976), Duviols (2003) y Burga (2005).

Hay, empero, una novedad fundamental en este último encuentro dialógico. El autor del libro redactado "en un castellano retorcido, lleno de errores gramaticales y con incontables términos y aun frases enteras en idioma quechua" (Miguel León-Portilla), no renuncia al uso de la letra para inscribir en ella la versión india de la Conquista. Emplea, por el contrario, el emblema del poder colonial, pero solo para subvertir sus ficciones, entre ellas las narraciones que transfiguran el rechazo inca del Libro en el pecado indio legitimante de la conquista del mundo andino. La única violencia que inicia el larguísimo "día de la desventura", dice por ejemplo Poma de Ayala, es la de los conquistadores que mataron indios como hormigas, sin razón ni justicia, el 16 de noviembre de 1532.

Valiosos estudios sobre las crónicas indígenas del Perú, particularmente sobre Relación de la conquista del Perú de Titu Cusi Yupanqui (1570), Relación de antigüedades deste Reyno de Joan de Santacruz Pachacuti Yanqui Salcamaygua (1613), y Primer nueva corónica y buen gobierno de Guaman Poma de Ayala (1615) hacen visible ampliamente la significación polémica, contestataria, del empleo indio de la letra en la América virreinal. Ello ahorra detallar aquí el proceso mediante el cual la escritura y el mismo acto de escribir devienen en dichas crónicas un espacio de lucha y resistencia. Lugar sobre todo de una paradoja: "(La génesis de estas narraciones es una singular asunción de lo irremediable. Reconocen) la importancia del signo, cifra y clave de la cultura hegemónica. Sin embargo, estos textos rescatan esa otra versión de la historia que la cultura dominante se esfuerza por borrar. Ellos son contemporáneamente revolucionarios por vincularse al proceso de descolonización que nos compele a rescatar y asumir el mundo negado" (Chang-Rodríguez 548). Paradoja, sin duda, del uso indio de la letra, pero también del empleo español de la voz. La Araucana de Ercilla es el ejemplo solo más espectacular de dicha contradicción. También lo es Armas antárticas. El autor del poema representativo de la "segunda fundación" del Perú otorga en él un amplio espacio textual a las palabras lascasistas de Atahualpa y Felipe. El fin del artificio es sublimar a los defensores del Perú a expensas de sus conquistadores. El fracaso de este proyecto estético y a la vez político es notable. El poseedor de la letra épica, del sentido en el mundo colonial, no logra controlar el contagio de lo revelado por la voz trágica de los muertos de Cajamarca. El poema de Miramontes y la crónica de Poma de Ayala señalan de este modo una misma verdad, no obstante las abismáticas diferencias 
entre el texto indio que libera las "voces insolentes" y el texto español que las silencia: escribir sobre el "mundo (andino) al revés" es llorar.

El contexto dialógico del poema de los españoles ocupados en "conquistar, quietar y defender este reino" desvanece así escandalosamente el espejismo de la mudez de los vencidos. Las voces de los "indios peruanos" no quedaron mudas después de Cajamarca ni después de Vilcabamba. Persisten, por el contrario, en múltiples formas, desde su presencia subrepticia, marginal, enmascarada en la figura del "indio infame" de Armas Antárticas hasta su irrupción irreprimible en Primer nueva corónica y buen gobierno; desde sus huellas a veces imperceptibles en las crónicas españolas hasta su persistencia tenaz en las representaciones orales de la tragedia de Atahualpa (wanka), en el mito de Inkarrí, en el milenarismo del Taqui Ongo, en la resistencia del nuevo estado inca de Vilcabamba o en el desgarrador esfuerzo de Garcilaso por armonizar en su escritura una historia hecha pedazos. El poeta que comienza su relato con la expulsión literal y simbólica de dichas "voces insolentes" parece estar fascinado solo por el poder de la letra triunfante en Cajamarca. No logra por ello controlar las contradicciones de su relato que bien podrían explicarse por su cruce tenso con los relatos orales y escritos, indios y españoles, criollos y mestizos sobre la conquista de Perú ¿Puede comprenderse si no que Pizarro, el conquistador devaluado en el Canto I por su inclemencia antiépica, sea el mismo Marqués que el sabio intérprete del porvenir de las figuras labradas en una sala del palacio prehispánico de Chuquiaquilla llama conquistador "digno de fama eterna y triunphal carro", merecedor de ser colocado "sobre la excelsa cumbre al cielo junto" (octava 1153), sin ninguna mención al pecado de Cajamarca?

El "indio infame" del Canto I es el personaje acaso más inquietante, siempre más acá o más allá de un sentido unívoco, de Armas antárticas. La intención deliberada del autor de Armas antárticas, propone Firbas, es convertir a Felipe en mediador del lascasismo para criticar a través de su voz los excesos "también fundacionales" de la conquista (194). La fuerza desintegradora de la palabra india en el poema no se consume, con todo, en el despliegue de las preguntas destinadas a evidenciar la injusticia de la muerte de Atahualpa ni en la sorprendente revelación de la especularidad del pecado del intérprete con el pecado del conquistador. Los mayores efectos de la fuerza crítica del traidor que muere proclamando la inocencia del Inca están realmente en otros lugares que en los ya mencionados. Se encuentran, por ejemplo, en la octava 58 del poema. Felipe establece aquí dos verdades con consecuencias imprevisibles en el proyecto estético y político de Miramontes. La primera 
descubre lo indecible en un poema heroico: la honra es vanidad que disimula la avaricia empleando los nombres de los "altos designios de gloriosa fama". La segunda recuerda la promesa de vida de la divinidad española: "(Dios) no quiere que muerte o mal reciba, / sino que se convierta el hombre y viva". Imprevisibles, porque la honra y la fama, madres de las virtudes heroicas, pueden convertirse en atributos sospechosos de enmascarar la ambición y la codicia, madres de todos los vicios humanos. Materia de bestiario, como en la Brevísima relación de la destrucción de las Indias de Bartolomé de las Casas, pero no de epopeya, como intenta serlo Armas antárticas. Hay, con todo, una respuesta tranquilizadora en la escritura de Miramontes: los dualismos vicio/virtud, exceso/norma, ofensa/castigo, entre otros, permiten diferenciar precisamente entre los conquistadores del Perú y los defensores del Perú. Pizarro, por ejemplo, versus Toledo. Tal disyunción, dominante en el poema antártico, es posible, pero solo funciona a expensas de un intenso mecanismo de borraduras en el retrato de los protagonistas de la época de la defensa de la "integridad católica" dañada en el Virreinato y en Europa por la "prevaricante apostasía". Un ejemplo notable entre los olvidos que intentan mantener sin mayores fisuras el espejismo épico en el tiempo de las confrontaciones de los imperios europeos en el Nuevo Mundo es el relato del trágico fin de Túpac Amaru (Canto XIII). Una figura se destaca con singular nitidez en los retratos heroicos descifrados por Curiñave en el palacio de Chuquiaquilla. Es don Francisco de Toledo, el virrey de Perú que aniquila la resistencia inca en Vilcabamba. Túpac Amaru, nos recuerda la nota de Firbas sobre el verso f de la octava 1171, fue capturado por un batallón dirigido por García de Loyola y llevado al Cuzco, donde el virrey Toledo ordenó su decapitación. Miramontes no enjuicia esta ejecución a través de Curiñave, como antes juzgó a Pizarro a través de Felipe. El indio venerable del Canto XIII, antítesis prehispánica del indio traidor del Canto I, emplea solo la octava 1171 para narrar la otra gran catástrofe que cierra (ilusoriamente) en el poema el círculo trágico de los incas prisioneros de los españoles. ¿Por qué Miramontes no utiliza aquí la misma imaginación metamorfoseadora de Pizarro y Felipe en dobles monstruosos de la violencia colonial? ¿Por qué se silencia que Túpac Amaru es, como Atahualpa, un personaje profundamente trágico, igualmente engañado, traicionado? ¿Por qué es repudiable la impiedad de Pizarro en Cajamarca, pero no la de Toledo en Vilcabamba? "A Toledo no le faltó justicia, le faltó la clemencia" (Levillier, cit. en Barros 64). El poeta prisionero de los espejismos épicos de una nueva elite colonial olvida aquí el principio analógico empleado en el Canto I para poder desprestigiar 
el panteón del "primer ciclo épico" del Perú. El lector del Canto XIII, sin embargo, recuerda las palabras insolentes de Felipe: "Un vivo ejemplo soy desta experiencia, / donde como en espejo puedes verte" (octava 61). No olvida lo que el autor enseña generosamente a través del "indio infame", sin advertir los riesgos a los que expone su propio proyecto mitificador de las "armas antárticas". El relato de la catástrofe de Cajamarca adquiere en este sentido significaciones insospechadas, irreductibles al travestismo lascasista de Felipe. Hace visible sobre todo el poder delirante de la (anti)utopía de la mudez del otro, sin guerra "pública ni secreta", en un mundo bellamente heterogéneo, prodigiosamente impuro ${ }^{9}$. Una sola religión, un solo rey, un solo idioma. Ahí donde las letras y las armas proclaman el silencio del otro, el traductor del Canto I desentraña el verdadero pecado fundador del Perú: las letales bodas de la "metástasis de lo Mismo" con la "brevísima destrucción" de las Indias: "Dios no quiere que muera o mal reciba, / sino que se convierta el hombre y viva". Los efectos disolventes del discurso de Felipe no se cortan ahí donde el poeta quiere cortarlos. El principio analógico que ellas

9 La octava 430 testimonia en este aspecto la hostilidad (acaso la secreta fascinación) del texto contra los descontrolados flujos del deseo liberados por las "bodas contra natura" (Deleuze y Parnet 5-60) o monstruosas ligas de luteranos y católicos, protestantes y cimarrones: "Todos en torno de la mesa estaban /sin que del negro al blanco diferencia/ hubiese, do los gustos se recreaban /en dulce y agradable complacencia. /Y a menudo y sin orden se brindaban, /tomando en el beber larga licencia,/ hasta que lenguas, ojos y sentidos / sienten del fuerte vino entorpecidos". Los límites entre lo negro y lo blanco son superados de modo radical. No disyunción ni binarismo, sino mezcla y oscilación. Las fronteras entre diferentes así desintegradas son precisamente las que la escritura de Miramontes se propone defender y perpetuar, esto es, los convenios "regulados" con la diferencia. El banquete de lo indomesticado cifra así literariamente la fuerza desestabilizante por excelencia de la atracción por lo otro en esas áreas de identidad incierta del poema que constituyen una especie de tierra de nadie y de todos. Briazo (inglés luterano) y Marta (negra cimarrona), pero también Oxnán (inglés luterano) y Estefanía (española católica): lugares "de encuentros permanentes, de fricciones que electrizan el aire. Combates, cópulas: fértiles impurezas. Traiciones y pactos. Promiscuidad. Vida de alta tensión" (Sánchez Sinisterra 267). Desde las zonas fronterizas no se perciben las fronteras. Miramontes, sin embargo, las percibe con toda nitidez. El final infeliz de todas las "bodas contra natura" así lo testimonia. Armas antárticas, no silencia, como en el relato de la mudez del mundo andino, la heterogeneidad de estos flujos de vida de "alta tensión" que contagian con "fértiles impurezas" los espacios fronterizos de la geografía colonial. Muestra las "fértiles impurezas", los flujos, los encuentros que disuelven los binarismos del discurso colonial, pero los corta, los castiga. Los desenlaces de estos "otros encuentros" son, por ejemplo, siempre trágicos. 
instauran despoja a los conquistadores de su prestigio heroico (Cantos I-II), pero también a los defensores de Perú (Cantos III-XX). Es el enigma que nos obsesiona: ¿qué letra, pero también qué voz, traduce el "indio infame”?

Misterio inexplicable porque se oculta en el mismo momento que se revela. Creemos haberlo agotado, pero descubrimos que ni hemos comenzado. Ello porque todavía falta preguntar, por ejemplo, a quién más traiciona de modo impensado el traductor de Atahualpa, Pizarro y Dios. No se trata ya, en este caso, de la significación del episodio de la profecía y muerte del "indio infame" en el tiempo de lo narrado, sino en el de la narración. Aquí, en este otro nivel, Felipe traiciona también escandalosamente a Miramontes. Recordamos, por medio de la lectura de Paul Firbas, nuestro intérprete letrado, que la transfiguración de Felipe en portavoz de un discurso lascasista permite al autor criticar "desde el mismo campo de batalla" las "malas hazañas" de los primeros conquistadores desde la perspectiva de una nueva elite de militares y funcionarios del virreinato (104). El artificio así descrito tiene gran interés para reflexionar sobre lo que hace posible la escritura misma de Armas antárticas. Nos referimos a los "intercesores", sin los cuales, según Deleuze, no hay literatura: "Lo esencial son los intercesores. La creación son los intercesores. Sin ellos no hay obra (...) Yo necesito a mis intercesores para expresarme, y ellos no podrían llegar a expresarse sin mí: siempre se trabaja en grupo" (Conversaciones 200). Los nombres de los personajes que permiten a Miramontes la escritura de Armas Antárticas como acto de seducción para atraer a los lectores hacia la verdad de la nueva elite colonial son varios: Atahualpa, Felipe, Arana, Rumiñave, Drake y el "viejo sagaz" son los más (a)notables. Los intercesores del relato de la conquista propiamente tal, empero, son solo dos: Atahualpa y Felipe. El Inca y el Traidor cifran aquí de modo clandestino, subrepticio, el discurso de los vencidos que, más allá de traducir el lascasismo desacreditador de la "mala hazaña" de Pizarro, revela una diferencia radical con el discurso de los vencedores. ¿Qué otra cosa si no es así testimonia la fricción Valverde / Atahualpa-Felipe en el interior del Canto I? Voz del intérprete Valverde: “Tú, Dios de los ejércitos, (...) te suplico esta ofensa satisfagas, / ésta, entre tantas maravillas, hagas" (octava 30). Voces de Atahualpa y Felipe: "Ya prevenido estoy, que anoche en sueños / me dio una voz de furia y terror llena, / un Dios horrible y de iracundos ceños (...) Estaba puesto el reo en el suplicio / y del Inga acordándose inocente, / dijo: 'Tu noble sangre a Dios justicia / está pidiendo, Rey, de mi malicia (...) ¿Con tus contrarios fue confederado (Atahuallpa)? / ¿Hízote algún notable vituperio? ¿Hubo por fuerza de arma ocupado / tierras 
sujetas al romano imperio? / ¿Negado la obediencia? ¿Ha quebrantado / de tu sagrada religión misterio?"(octavas 28 y 54). Violencia "sin razón ni justicia" del Inca: injuria del Libro. Violencia sin razón ni justicia de los españoles: masacre de Cajamarca. La disonancia de estas dos versiones de la "escena primordial" peruana es irreductible. El lector puede caer en la trampa del artificio que desplaza el centro del debate sobre el origen de la violencia colonial, pero la escisión de los relatos simétricamente invertidos persiste imborrable. Los efectos de ello para la configuración del espejismo épico de la defensa del Perú contra Inglaterra, materia misma de Armas antárticas, son realmente irreparables. Nada impide, por ejemplo, el contagio del empleo de la imaginación de los gemelos enseñada por Felipe. El doble monstruoso de Pizarro en Cajamarca es el "indio infame", pero también lo son Francisco de Toledo, Hurtado de Mendoza, Óñez de Loyola y Sarmiento de Gamboa en Vilcabamba. La oposición entre las "malas hazañas" de la conquista del Perú y las "buenas hazañas" de su defensa se desvanece estrepitosamente con la memoria de los olvidos y silencios de Miramontes en el retrato de los varones ilustres pintados en el palacio prehispánico de Chuquiaquilla. Los héroes del relato legitimante de la nueva elite militar y funcionaria del Perú se constituyen como tales solo a expensas de la borradura de sus hazañas en Vilcabamba y la Araucanía. Las voces indias, convocadas secretamente por las de Felipe en todos los cantos dedicados a los héroes del mundo antártico, se vengan así del poema que proclama públicamente la mudez de los "indios peruanos" en el tiempo de su escritura. La "fuerza débil" de la voz corroe implacablemente la "fuerza fuerte" de la letra. El heroísmo verdadero, que siempre se templa con la clemencia, dice Miramontes, se cifra en los defensores del mundo antártico. Mentira, replica la voz irreductible de Felipe: el heroísmo verdadero no existe en el ciclo épico de la conquista del Perú ni en el ciclo de su defensa. Los verdaderos dobles monstruosos de Pizarro no se encuentran en el mundo andino. Felipe, por ejemplo, lo es solo en el artificio destructor del prestigio heroico de los conquistadores del mundo andino (Canto I). Se encuentran realmente en un lugar no previsto por Miramontes: el mundo antártico. Ahí, en el epicentro mismo del canto del poeta, los reflejos de la figura del espejo inventada por el traductor indio iluminan lo que el poema debe tachar, hacer olvidar para construir sin fisuras el panteón épico de la elite que en él intenta su legitimación simbólica: las "fechas negras", infames, de Toledo, Mendoza, Loyola y Gamboa.

Nosotros, los occidentales, leemos en La transparencia del mal, descubrimos que nada de lo que creíamos superado en la marcha hacia el progreso 
universal ha muerto realmente, porque todo resurge, no como vestigio arcaico o nostálgico sino con una vehemencia y una virulencia absolutamente modernas en el corazón de nuestros sistemas ultrasofisticados y ultravulnerables, estropeándolos sin esfuerzo alguno (Baudrillard 148). Este desquite, que Baudrillard descubre en el siglo XX, es ya perceptible con toda nitidez en la época colonial. Armas antárticas así lo testimonia en los inicios del siglo XVII. Miramontes está persuadido de la mudez de las voces indias en el tiempo de la defensa del Perú. No advierte por ello los peligros de conceder la palabra al intérprete indio. La criatura profética del Canto I obedece a su creador cuando deshace el aura de los héroes de la conquista del mundo andino, pero se insubordina cuando desacraliza igualmente a los protagonistas de la epopeya de la defensa del mundo antártico. El indio Felipe deviene así doblemente infame: traiciona a Atahualpa en el tiempo del enunciado y a Miramontes en el tiempo de la enunciación. Chivo expiatorio en el texto y a la vez chivo expiatorio del texto, la figura acaso más desestabilizadora de las estrategias de seducción de Armas antárticas lo es sobre todo porque su "presencia fantasmal, viral, espectral" cifra poéticamente, a pesar o en contra de los designios reductores de la letra épica, "la fatalidad indestructible" de la Alteridad" (Baudrillard): regla del mundo que el libro de Miramontes, prisionero del mito de la mudez de los vencidos, muestra sin descubrirla, testifica sin revelarla.

La lectura de Paul Firbas que nuestra lectura reafirma al mismo tiempo que la reelabora, como lo requiere el imperativo doble de la herencia, abre pues una caja de Pandora llena del "sonido y furia y noche y escarlata" (Borges, III, 181) de la multiplicidad de discursos que constituyen el "contexto dialógico" de Armas antárticas. ¿Quién diría que el poema así leído contiene la memoria de todos los males engendrados en Cajamarca? Los muertos no vuelven en el mito de Hesíodo, pero, "nos dice la caja de Pandora", son siempre nuestros contemporáneos. Eso que testimonia, precisamente, el relato de la tragedia de Cajamarca en Armas antárticas: "No sobra añadir que (las distintas versiones de la historia de Cajamarca) no agrega(n) nada nuevo sino confirman lo que todos saben (la captura y muerte del Inca en Cajamarca), pero ese episodio, como está dicho tiene algo así como una ubicuidad temporal por la cual dicho episodio central está allá y en el tiempo pasado, pero también aquí y en el tiempo presente" (Cornejo Polar 87). Perturba en este aspecto el hallazgo de la imagen de la caja dentro de la cual, después de salir de ella todos los males, permanece en su interior solo la Espera (Hesíodo 67-68). Algo queda, en efecto, después de la irrupción de las voces convocadas clandestinamente 
por el intérprete traidor. Es, precisamente, el discurso de la esperanza de los vencidos: "Atavalipa dixo (...) que le volverían a ver hecho culebra" (Cieza de León, III, 170). "Dichos dellos", en síntesis, con los cuales el contexto dialógico del poema antártico carga, a expensas del proyecto estético y político de su autor, al relato de Cajamarca con "nuevas experiencias y de nuevos sentidos y hasta gestando, en algunos casos, contenidos que hablan de un futuro que corregirá el desorden cósmico que se inició con la Conquista" (Cornejo Polar 87). Este es acaso el bello secreto del poema leído desde la voz enigmática del "indio infame" (y de Atahualpa), desde la resistencia al perfume embrujador del texto de la (imposible) mudez de los vencidos que Firbas abre a la lectura poética y el diálogo crítico. La historia, se advierte entonces, no está detenida ni congelada, como Miramontes intenta hacerlo por intercesión de Curiñave en el palacio prehispánico de Chuquiaquilla, sino en plena ebullición. Memoria del pasado es sin duda Armas antárticas pero también memoria del porvenir. Miramontes fracasa doblemente en su organización de la amnesia mediante la sublimación de la violencia fundadora del Perú. No logra la desaparición sin huellas de las voces de los vencidos del ciclo épico andino, ni impedir la irrupción disolvente de dichas voces en la sublimación épica de los protagonistas del ciclo épico antártico. Aquí reside, sin embargo, la clave de la contemporaneidad de su poema en este tiempo de la "desestabilización sin recurso, la del sujeto sin objeto, la del mismo sin el otro: estasis definitiva y metástasis del Mismo" (Baudrillard, El crimen perfecto 153). Armas antárticas, poema trunco dos veces, lo es por el deseo imposible, irrealizable, de consumar simbólicamente en su interior el crimen perfecto: la desaparición del otro. Los ecos de las insolentes voces de Felipe y Atahualpa testimonian lo inconcebible en el discurso explícito de Armas antárticas. El crimen nunca es perfecto porque "la alteridad radical resiste a todo: a la conquista, al racismo, al exterminio, al virus de la diferencia, al psicodrama de la alienación" (Baudrillard, La transparencia del mal 156). "Fatalidad indestructible" del Otro: Felipe y Atahualpa o el Gran Juego. Lautaro y Galvarino o la Regla del Mundo: de una parte, las alteridades llamadas indio peruano, luterano, aindiado, fugitivo, cimarrón, araucano o indio magallánico están siempre muertas en Armas antárticas, La Araucana, Arauco domado o Purén indómito; de la otra, son indestructibles. Descubrimiento de la idea, testimonio de los hechos, revelación de la literatura: "muertos podremos ser, mas no vencidos, / ni los ánimos libres oprimidos".

Caja de Pandora, acaso, pero también masa de sentidos. El editor crítico de Armas antárticas desencanta sus versos no solo para lo que Bajtin denomina 
tiempo menor (la actualidad, el pasado reciente y el futuro deseado), sino también para el gran tiempo, que es un diálogo infinito e inconcluso en el cual no muere ni uno solo de los sentidos (Estética de la creación verbal 391). El poema de Miramontes estuvo silencioso durante varios siglos. Nada suyo, sin embargo, está muerto de una manera absoluta. Cada uno de sus sentidos, por el contrario, espera su fiesta de resurrección. Acaso Firbas solo ha abierto un libro. No, sin embargo, cualquiera "cosa entre las cosas", sino también un arma, como lo es Macbeth en "Un libro" de Borges: "Mi palma la sopesa. Quien diría / Que contiene el infierno: las barbadas / Brujas que son las parcas, los puñales / Que ejecutan las leyes de la sombra" (181). Arma cargada con el sueño colonial del crimen perfecto: la mudez, "pública y secreta", del vencido y el olvido de la verdad de los dobles monstruosos. Delirio que el mismo texto, malgré lui, volatiliza. Imperio de la letra que la voz insolente de Felipe invade de tal modo que lo convierte en ilusorio. Proyecto doblemente frustrado de organizar la amnesia de la violencia fundadora del Perú. Victoria secreta de la voz sobre la letra. Crítica en acto de la ideología colonial. Verdad del Gran Juego que se revela en el lugar de su (intento de) silenciamiento. ¿Cómo rechazar si no la fascinación por el "tumulto silencioso" de las voces convocadas subrepticiamente por el "indio infame" de Armas antárticas? Ese tumulto que ahora, por primera vez en su edición crítica completa, duerme en los tranquilos anaqueles del archivo colonial. Duerme y espera.

Un viaje entre la atracción y el rechazo del embrujo de la belleza de la escritura de Miramontes y la de Firbas ha terminado, pero otro comienza. Es el viaje del barquito que unos niños sueltan y pierden, y que otros roban, cada uno con su botín sin dejar por ello de juntarse con los demás. El reinicio del círculo de la seducción que no se detiene y es inmediatamente reversible: atracción y suspensión del embrujamiento del canto regido por la ilusión del crimen perfecto. Reinicio del esfuerzo de reafirmar a la vez que reactivar nuestra herencia: "(la misma herencia ordena, para salvar la vida en su tiempo finito,) reinterpretar, criticar, desplazar, o sea, intervenir activamente para que tenga lugar una transformación digna de tal nombre: para que algo ocurra, un acontecimiento, la historia, el imprevisible por-venir" (Derrida y Roudinescu 12). Exhortación "contradictoria e incómoda", pero plausible cuando el "contacto dialógico" de Armas antárticas con textos escritos y orales de su tiempo termina revelando lo inconcebible: el triunfo de las voces insolentes sobre las letras que proclaman su silencio. Las voces nunca mudas, precisamente, de la historia, el mito y la literatura que hoy como ayer 
nos interpelan para revelar el Gran Juego de la "fatalidad indestructibe" de la alteridad, para recordar entre los signos de la reversión del embrujo de la pantera épica que las huellas del futuro están en el pasado. Estos rastros parecen no existir en Armas antárticas, pero esperan su des-cubrimiento. Ahí, en el espacio donde "no existe ni la primera palabra, y no existen fronteras para un contexto dialógico (que) asciende a un pasado infinito y tiende a un futuro igualmente infinito" (Bajtin, Estética de la creación verbal 392), dichos signos preñados de futuro duermen en tranquilos anaqueles y sueñan la fiesta de su resurrección, el renacimiento de sus sentidos olvidados. Esperan la consumación de su poder para desordenar de modo radical la organización de la amnesia de la violencia de la conquista y la defensa del Perú. Irrupción desquiciante de tal modo que las ficciones coloniales terminan revelando, contra ellas, la reverberación de las huellas del "único acontecimiento digno de tal nombre". Eso que ilumina fugazmente Armas antárticas en la inscripción más bella del palacio de Vilcabamba. Rumiñave no pudo o no quiso traducirla. Únicamente hoy, cuando el contacto dialógico del poema completo con las crónicas, historias, otros poemas épicos y múltiples narraciones orales de su tiempo permite liberar las "voces insolentes" de su condena a ocultar la verdad antiépica de la proliferación de los dobles monstruosos en la conquista y la defensa del Perú, es posible descifrar la verdad salvadora: solo allí donde el otro que se manifiesta en el "no matarás" inscrito en su rostro puede llegar y ser acogido hay por venir o un porvenir.

Intervenir, criticar, desplazar la herencia para que algo ocurra: deuda del heredero con lo que lo precede y también con lo venidero. Es la anacronía descrita por Derrida en $Y$ mañana, qué...: " anticipar en nombre de aquello que se nos anticipa, ¡anticipar el mismo nombre! ¡Inventar su nombre, firmar de otra manera, de un modo siempre único, pero en nombre del nombre legado, de ser posible!" (63). Recibimiento, robo y entrega del barquito de la herencia. Cada uno con su saco, con su firma, con su botín, sin dejar por ello de juntarse con los demás: Homero $y$ Virgilio $y$ Ariosto $y$ Cieza de León $y$ Garcilaso Inca de la Vega $y$ Huaman Poma de Ayala $y$ Miramontes $y$ Firbas $y$ Triviños $y$ Faúndez $y \ldots$ : diálogo infinito, sin primera ni última palabra, sobre el otro que nos interpela como espejo, peligro, seducción o destino: inagotable renovación de sus invenciones y contrainvenciones en todos los contextos nuevos: fiesta de atracción y rechazo de los signos del "embrujo de la belleza" de Armas antárticas en la cual la conjunción Y, que no es ni una reunión ni una yuxtaposición sino el nacimiento de un tartamudeo, el trazado de una línea de fuga activa y creadora" (Deleuze y Parnet 14), nos permite 
firmar de otro modo, sin dejar por ello de celebrar las firmas de Miramontes y de Firbas, nuestra lectura del espejismo de la desaparición sin huellas del otro en Armas antárticas: el sueño de un "crimen perfecto" que aún nos atrae con sus perfumes embriagadores.

\section{BIBLIOGRAFÍA}

Anónimo. El cantar de Rolando (Traducción, prefacio y notas de Braulio Arenas). Santiago: Editorial Nascimento, 1982.

Barros, José Miguel. Pedro Sarmiento de Gamboa. Avatares de un caballero de Galicia. Santiago de Chile: Editorial Universitaria, 2006.

Bajtin, M.M. Yo también soy (Fragmentos sobre el otro). México: Taurus, 2000. Estética de la creación verbal. México: Siglo XXI Editores, 1985.

Baudrillard, Jean. La ilusión vital. Buenos Aires: Siglo Veintiuno Editores, 2002. De la seducción. Madrid: Ediciones Cátedra, 1998. El crimen perfecto. Barcelona: Anagrama, 1997. La transparencia del mal. Barcelona: Anagrama, 1991.

Baudrillard, J.; Guillaume, M. Figuras de la alteridad. México: Taurus, La huella del otro, 2000.

Borges, Jorge Luis. Obras Completas, III. Buenos Aires: Emecé Editores, 1991.

Burga, Manuel. Nacimiento de una utopía. Muerte y resurrección de los incas. Lima: Universidad Nacional Mayor de San Marcos y Universidad de Guadalajara, 2005.

Cornejo Polar, Antonio. Escribir en el aire. Ensayo sobre la heterogeneidad socio-cultural en las literaturas andinas. Lima: Editorial Horizonte, 1994.

Chang-Rodríguez, Raquel. Franqueando fronteras. Garcilaso de la Vega y La Florida del Inca. Edición, introducción y notas de Raquel Chang-Rodríguez. Lima: Pontificia Universidad Católica del Perú, 2006.

De Cieza de León, Pedro. Crónica del Perú. Tomos I, II y III. Edición, prólogo y notas de Francesca Cantú. Lima: Fondo Editorial de la Pontificia Universidad Católica del Perú, 1986.

De Miramontes Zuázola, Juan. Armas antárticas (Estudio, edición crítica y notas de Paul Firbas). Lima: Fondo Editorial de la Pontificia Universidad Católica del Perú, 2006.

De Pagés, A. y Pérez H., J. Diccionario de la lengua castellana (De Autoridades). Cinco tomos. Barcelona: Imprenta de Ángel Ortega, Editorial Selección, s/f.

Deleuze, Gilles. Conversaciones. Valencia: Pre-Textos, 1995.

Deleuze, G. y Parnet, C. Diálogos. Valencia: Pre-Textos, 1997.

Derrida, Jacques. El siglo y el perdón seguido de Fe y saber. Buenos Aires: Ediciones de la Flor, 2003 
Derrida, J. y Roudinescu, E. Y mañana qué... Buenos Aires: Fondo de Cultura Económica de Argentina, S. A, 2003.

Duviols, Pierre. Procesos y visitas de idolatrías. Cajatambo, siglo XVII. Lima: Fondo Editorial de la Pontificia Universidad Católica del Perú - Instituto Francés de Estudios Andinos, 2003.

Ercilla, Alonso de. La Araucana. Barcelona: Editorial Iberia, Obras Maestras, 1962

Firbas, Paul. "Una lectura: los héroes en el mapa colonial". En De Miramontes, Juan. Armas antárticas (Estudio, edición crítica y notas de Paul Firbas). Lima: Fondo Editorial de la Pontificia Universidad Católica del Perú, 2006.

Henríquez Ureña, Pedro. Las corrientes literarias en América Latina. México, D. F.: Fondo de Cultura Económica, 1954.

Hesíodo. Obras y fragmentos. Madrid: Editorial Gredos, 2000.

Juarroz, Roberto. Duodécima poesía vertical. Buenos Aires: Ediciones Carlos Lohlé, 1991.

León-Portilla, Miguel. El reverso de la conquista. Relaciones aztecas, mayas e incas. México: Editorial Joaquín Mortiz, 1964.

Ortiz Rescanieri, Alejandro. De Adaneva a Inkarrí: Una visión indígena del Perú. Lima: Eds. Retablo de Papel, 1973.

Piglia, Ricardo. Crítica y ficción. Buenos Aires: Editorial Planeta , Argentina, S.A.I.C / Seix Barral, 2000.

Poma de Ayala, Felipe Guaman. Nueva Corónica y buen gobierno. Tomos I y II. Transcripción, prólogo, notas y cronología de Franklin Pease. Caracas: Biblioteca Ayacucho, 1980.

Sánchez Sinisterra, José. Naque. ¿Ay, Carmela! Madrid: Ediciones Cátedra, 1991.

Wachtel, Nathan. Los vencidos. Los indios del Perú frente a la conquista española (15301570). Madrid: Alianza Editorial, 1973. 